\title{
Metronomics as maintenance treatment in oncology: time for chemo-switch
}

\author{
Prabhat Singh Malik ${ }^{1,2}$, Vinod Raina ${ }^{2,3}$ and Nicolas André $e^{2,4,5 *}$ \\ 1 Department of Medical Oncology, Dr. BRAIRCH, All India Institute of Medical Sciences, New Delhi, India \\ ${ }_{2}^{2}$ Metronomics Global Health Initiative, Marseille, France \\ ${ }^{3}$ Fortis Memorial Research Institute, Gurgaon, India \\ ${ }^{4}$ Service d'Hématologie et Oncologie Pédiatrique, AP-HM, Marseille, France \\ ${ }^{5}$ INSERM UMR 911, Centre de Recherche en Oncologie Biologique et Oncopharmacologie, Aix-Marseille University, Marseille, France \\ *Correspondence: nicolas.andre@hp-hm.fr \\ Edited by: \\ Silvia Giordano, University of Turin, Italy \\ Reviewed by: \\ Silvia Soddu, Regina Elena Cancer Institute, Italy
}

Keywords: metronomic chemotherapy, maintenance, chemo-switch, global perspective, low-dose chemotherapy

The "cell kill" paradigm associated with maximum-tolerated dose (MTD) chemotherapy has shown remarkable success in many hematological malignancies, but unfortunately has failed to demonstrate sustained responses in majority of common advanced solid tumors. This failure can be attributable to heterogeneity of cancer cells within the tumor in terms of the rate of cell proliferation, genetic makeup, and micro-environmental selection giving rise to development of treatment resistance. In this context, Gatenby's hypothesis of controlling tumor growth rather than eradicating it and treating it like a chronic disease may be more meaningful (1). The use of metronomic regimens alone or in combination with other new targeted therapies after MTD chemotherapy as maintenance treatment for longer period may pave the way for long-term cost-effective treatment.

\section{METRONOMIC CHEMOTHERAPY}

Metronomic chemotherapy (MC), a term initially coined by Hanahan, is defined as administration of chemotherapeutic agents at relatively low, minimally toxic doses, and with no prolonged drug-free breaks (2). This concept originated by pioneer work done by Klement et al. and Browder et al. showing that mice bearing subcutaneous tumors could respond to frequent repeated low doses of chemotherapy, even when they displayed acquired drug resistance to the same agents given in a conventional way $(3,4)$.

Several mechanisms of action have since been proposed for MC, the major being the inhibition of angiogenesis by selective inhibition of proliferation and/or induction of apoptosis of activated endothelial cells, selective inhibition of endothelial cell migration, increase in the expression level of the endogenous angiogenesis inhibitor thrombospondin-1, and sustained decrease in levels and viability of bone marrowderived endothelial progenitor cells (5). In addition, $\mathrm{MC}$ has immuno-modulatory effect through Treg depletion, NK cell and $\mathrm{T}$ cell activation, and promoting dendritic cell activation $(5,6)$. Overall, these properties may lead to re-induction of tumor dormancy. Therefore, MC can be regarded as an intrinsically multi-targeted therapy $(5,7)$.

The use of MC in the clinic practice has been mainly limited to palliative purposes in relapse/refractory diseases, with good response rates and a favorable toxicity profile. In a recent systemic review of 80 small single arm and phase II studies of low-dose $\mathrm{MC}$ in various tumor types including 3700 patients, Lien et al. showed mean response rates of $26 \%$, median progression-free survival (PFS) of 4.6 months, and mean disease control rates of $56 \%$. Grade $3 / 4$ adverse events were found to be rare (anemia $8 \%$, fatigue $13 \%$ ) (8). Building on these encouraging results, nine phase III trials are currently registered at ClinicalTrials.gov in various clinical settings including adjuvant and maintenance.

\section{MAINTENANCE TREATMENT: SCOPE IN VARIOUS SOLID TUMORS}

The U.S. National Cancer Institute's (NCI's) medical dictionary defines maintenance therapy as "type of treatment that is given to prevent progression after it has been controlled successfully with the initial therapy." It includes treatment with drugs, vaccines, or antibodies with anticancer properties and may be given for extended period of time. Aims of treatment in many advanced cancers are to prolong survival and improve patient's quality of life. An effective maintenance therapy should seek to achieve both of these goals with a good patient tolerance, lack of cumulative toxicities, and cost-effectiveness. In this context, two treatment paradigms have emerged; continuation maintenance where one component of initial therapy is continued after the induction treatment and switch maintenance in which a new and potentially cross-resistant agent is introduced (9).

Maintenance therapy has been classically used for hematological malignancies like acute lymphoblastic leukemia (ALL) $(10,11)$ and low-grade non-Hodgkin's lymphoma $(12,13)$. Recently, there has been a growing interest to explore the role of maintenance in various advanced solid tumors. Advanced non-small cell lung cancer (NSCLC), metastatic colorectal cancer (CRC), metastatic breast cancer, and ovarian cancer are few examples where maintenance treatments with either chemotherapy or targeted therapies have shown promising results. In NSCLC, most of the strategies of either continuation or switch maintenance demonstrated a significant improvement in PFS except for pemetrexed and erlotinib which also showed an overall survival (OS) improvement (9). A recent meta-analysis incorporating data of 
3736 patients from eight randomized controlled trials on maintenance treatment in advanced NSCLC altogether suggest, that OS and PFS are clearly in favor of maintenance therapy for both, switch and continuation strategy (14). Similarly for metastatic breast cancer, a meta-analysis including 2269 patients from 11 randomized trials showed a clear benefit of longer duration of chemotherapy in terms of PFS and OS (15). Several studies in metastatic CRC have demonstrated improvement in survival by continuing part of the induction chemotherapy and/or targeted agents beyond six cycles (16-18). The role of maintenance chemotherapy in ovarian carcinoma has been more controversial, different large randomized trials showing variable results $(19,20)$. Recent meta-analysis of 1644 patients from eight trials showed no benefit of maintenance chemotherapy in ovarian carcinoma (21). However, anti-angiogenic agents like bevacizumab have shown promising activity when combined with chemotherapy and continued as maintenance (22). In a recent phase II study, olaparib, an oral poly[adenosine diphosphate (ADP)-ribose] polymerase inhibitor has also shown benefit in terms of PFS when used as a maintenance therapy in platinum-sensitive relapse ovarian cancers (23). Results of an international Intergroup trial (AGO-OVAR16) presented at annual conference of American Society of Clinical Oncology (ASCO) in 2013 demonstrated a PFS benefit of pazopanib maintenance in advanced epithelial ovarian cancer (24).

\section{ECONOMIC AND QUALITY OF LIFE CONSIDERATIONS WITH MAINTENANCE TREATMENT}

Cost-effectiveness and quality of life are two other major issues associated with prolonged use of maintenance therapy. The economic impact of maintenance for advanced cancers has been studied in numerous cost-effectiveness analyses. For example, the incremental cost-effectiveness ratio (ICER) per lifeyear gained with maintenance pemetrexed in advanced NSCLC was estimated to be $\$ 205,597$ (25). Similarly, in ovarian cancer, economic evaluation of maintenance paclitaxel and maintenance bevacizumab demonstrated that compared with carboplatin-paclitaxel for six cycles, maintenance paclitaxel had an
ICER of $\$ 13,402$ per quality-adjusted lifeyear while addition of bevacizumab to carboplatin-paclitaxel and then as maintenance monotherapy had an ICER of $\$ 326,530$ per quality-adjusted life-year (26). In a systematic review, addition of bevacizumab to chemotherapy in metastatic CRC was also found not to be costeffective (27).

Tolerance and compliance of chronic treatment are major concerns but second line therapy on progression can also lead to global deterioration of quality of life due to disease-related symptoms which may in turn compromise the feasibility of second line treatment. To date, no clinical trial has demonstrated a significant improvement in quality of life with maintenance treatment as compared to observation. However, several studies have shown that global quality of life does not deteriorate, indicating the favorable toxicity profile of prolonged administration of single-agent cytotoxic or biological agents $(28,29)$.

Looking at maintenance with patient's perspective suggests that majority will prefer maintenance over observation alone. In a pilot survey of 30 patients, Peeters et al. showed that metastatic NSCLC patients in general were in favor of maintenance and accepted either an OS benefit of at least several months, or better symptom control, in exchange for mild-to-moderate side effects. There was a slight preference for oral vs. intravenous administration (30).

\section{METRONOMICS AS MAINTENANCE THERAPY}

The concept of metronomic maintenance is not new. The success of this approach in ALL maintenance is the best and time-tested illustration (10). The effect of metronomic therapy on tumor microenvironment like inhibition of angiogenesis and immune modulation may be best utilized in maintenance setting when the disease burden is low. The "multitargeted-metronomic-MTD chemo-switch (C-S)" model is the proof of concept for this strategy (31). It consists of administration of MTD chemotherapy followed by multi-targeted anti-angiogenic maintenance therapy. Recently, Vives et al. have also demonstrated that in pancreatic tumor models, C-S schedule of MTD and metronomic gemcitabine had the most favorable effect. They also showed that in contrast with standard doses of chemotherapy, metronomic and C-S gemcitabine both affect the pancreatic cancer stem cell (CSC) population (32). Similarly, a study of glioma subcutaneous xenograft model has shown the sensitivity of CSC population to metronomic cyclophosphamide administration (33). It has been proposed that CSCs can play a role in the resistance to conventional chemotherapy and radiotherapy, therefore targeting CSCs or the stem cell niche through antiangiogenesis with C-S metronomic approach opens a new avenue for clinical and preclinical research. In a recent review on maintenance therapy in NSCLC, Gerber et al. have suggested metronomic maintenance as a biologically rational approach (9).

\section{CLINICAL EXPERIENCE OF METRONOMICS AS MAINTENANCE}

Although promising, metronomics as maintenance has not been extensively tested in clinical setting. Table 1 summarizes the clinical studies exploring role of metronomic therapies as maintenance. Most of these studies are small and single arm observations. However, a good safety profile and promising efficacy has been demonstrated by most of these studies. The results of a phase 3 trial (CAIRO3) were presented at annual meeting of ASCO in 2013. After randomization of 558 patients and median follow-up of 33 months, improvement in PFS and OS was demonstrated with the use of maintenance metronomic dose of capecitabine along with bevacizumab (34).

There are several ongoing clinical trials which are evaluating the role of metronomic maintenance in various combinations in colorectal cancer, breast cancer, and ovarian cancer (Table 1). The results of these trials will further clarify the utility of metronomic therapies as maintenance.

Three important aspects make metronomics appealing for maintenance: (1) favorable toxicity profile for long-term use. (2) The selection of low cost drugs for such regimens makes them widely practicable globally, especially in low and middle income countries (LMICs). (3) Their efficacy to target angiogenesis, CSCs, and immune modulation make them capable of overcoming resistance and delaying tumor progression. 


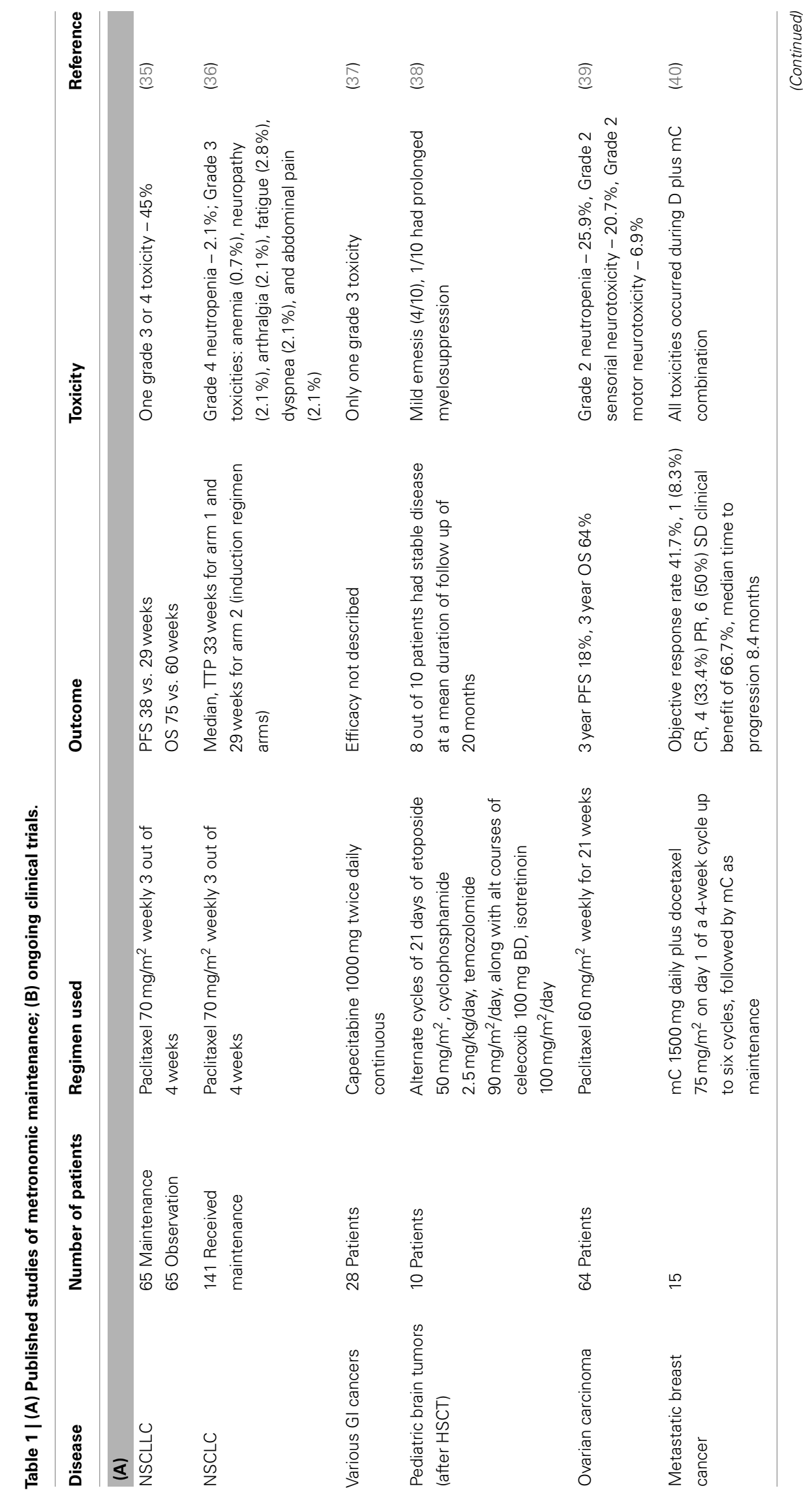




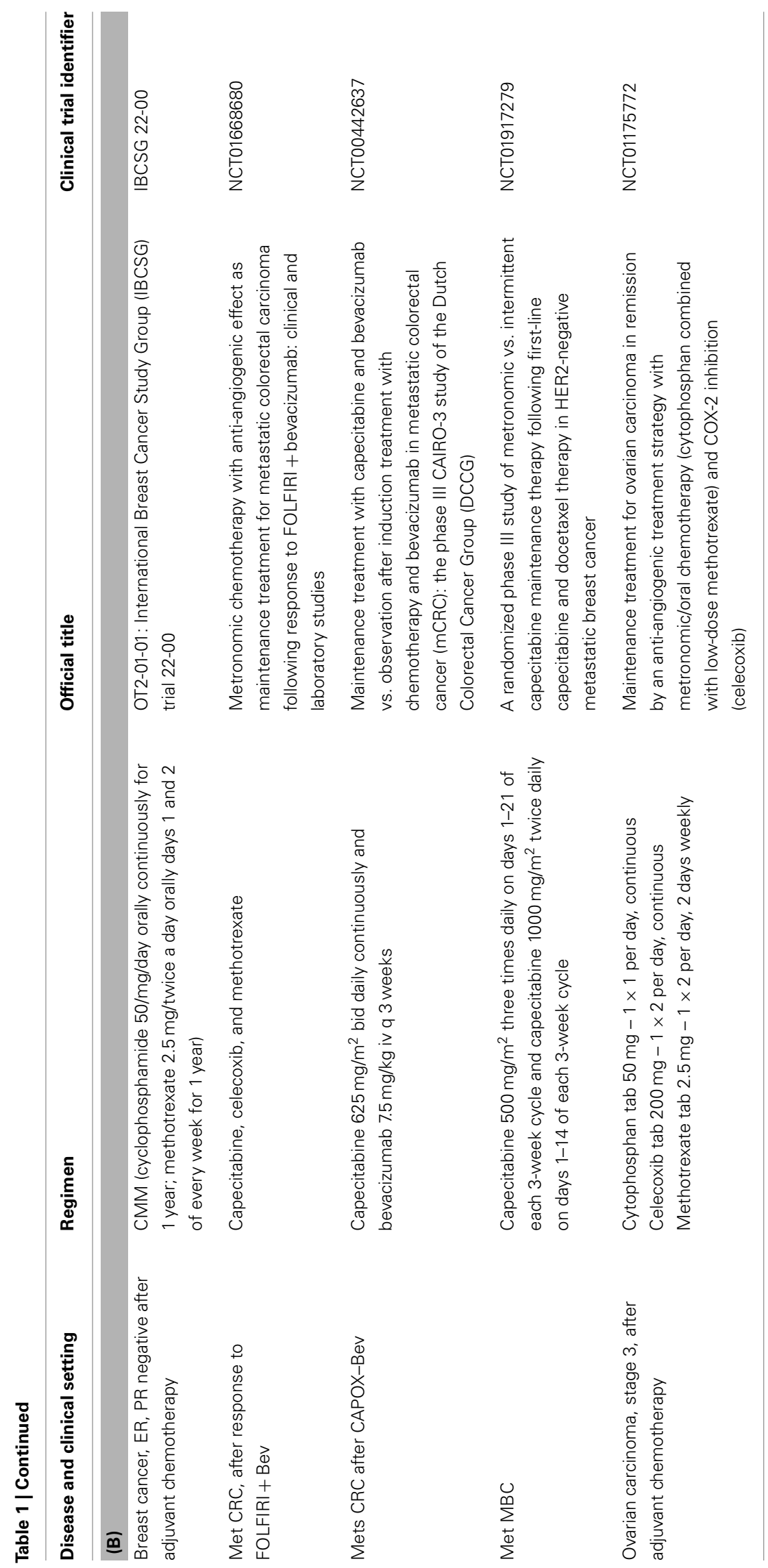




\section{POTENTIAL COMBINATION WITH TARGETED THERAPIES}

Combining MC with specific targeted therapies may eventually enhance the efficacy and specificity of a maintenance as demonstrated in several preclinical models and in the clinic (41-43). Noteworthy, the success of combination of targeted therapies with MTD chemotherapy has been variable and showed mostly failure when it was combined with anti-angiogenic TKIs in contrast to monoclonal antibodies (4447). On the other hand, several preclinical and early clinical studies have shown that MC could be successfully combined with Pazopanib, an oral multi-kinase inhibitor showing encouraging activity in gynecological cancer (48) and pediatric solid tumors (41). MC, in that case, can be used to bridge the gap between biologicals and cytotoxics (48). The potential benefit of long-term use of targeted angiogenic inhibitors and $\mathrm{MC}$ can be gainfully utilized in maintenance.

Repositioning of several other drugs like celecoxib $(49,50)$, metformin $(51,52)$, propranolol $(53,54)$, valproic acid $(55)$, atorvastatin (56), and itraconazole (57) which have shown anticancer properties in several preclinical, epidemiological, and clinical settings, can also be considered along with metronomic regimens for long-term use.

\section{GLOBAL ONCOLOGY PERSPECTIVE}

Ever-increasing cost of cancer treatment is a great public and political concern even in the developed world. In LMICs, where most of the new cancer cases and cancer deaths occur, access to most of modern treatment modalities is beyond imagination. High income countries' standards of care, although appealing, are out of reach for LMICs because of their cost, toxicities, and the complex infrastructure and technology needed. As we have proposed earlier, metronomics may be a promising alternative strategy for the improvement of cancer care in LMICs (58). This treatment strategy seems even more promising in maintenance setting where longterm administration is required and can be more acceptable because of favorable toxicity profile and affordable cost.

\section{CONCLUSION}

The field of metronomics still is terra incognita even after more than a decade since conception. The selection of best metronomic regimen for individual disease, the ideal combination and scheduling, predictive bio-markers, and the timing of institution are certain areas which still remain unanswered. Apart from relapse/refractory settings where this therapy has been tested mostly and showed meaningful activity, there is enough scientific rationale for their evaluation as maintenance strategy. Preclinical work for selection of drugs to be used, identification of predictive biomarkers, and rationale combination with other biological agents are some areas which warrant further research.

\section{ACKNOWLEDGMENTS}

We acknowledge European Society for Medical Oncology for providing "Clinical Unit Visit" fellowship grant to Prabhat Singh Malik to visit Nicolas André's institute.

\section{REFERENCES}

1. Gatenby RA. A change of strategy in the war on cancer. Nature (2009) 28(7246):508-9. doi:10. 1038/459508a

2. Hanahan D, Bergers G, Bergsland E. Less is more, regularly: metronomic dosing of cytotoxic drugs can target tumor angiogenesis in mice. J Clin Invest (2000) 105(8):1045-7. doi:10.1172/JCI9872

3. Klement G, Baruchel S, Rak J, Man S, Clark $\mathrm{K}$, Hicklin DJ, et al. Continuous low-dose therapy with vinblastine and VEGF receptor- 2 antibody induces sustained tumor regression without overt toxicity. J Clin Invest (2000) 105(8):R15-24. doi:10.1172/JCI8829

4. Browder T, Butterfield CE, Kräling BM, Shi B, Marshall B, O'Reilly MS, et al. Antiangiogenic scheduling of chemotherapy improves efficacy against experimental drug-resistant cancer. Cancer Res (2000) 60(7):1878-86.

5. Pasquier E, Kavallaris M, André N. Metronomic chemotherapy: new rationale for new directions. Nat Rev Clin Oncol (2010) 7(8):455-65. doi:10. 1038/nrclinonc.2010.82

6. Ghiringhelli F, Menard C, Puig PE, Ladoire S, Roux S, Martin F, et al. Metronomic cyclophosphamide regimen selectively depletes CD4+CD25+ regulatory $\mathrm{T}$ cells and restores $\mathrm{T}$ and $\mathrm{NK}$ effector functions in end stage cancer patients. Cancer Immunol Immunother (2007) 56(5):641-8. doi:10. 1007/s00262-006-0225-8

7. André N, Carré M, Pasquier E. Metronomics: towards personalized chemotherapy? Nat Rev Clin Oncol (2014) (in press)

8. Lien K, Georgsdottir S, Sivanathan L, Chan K, Emmenegger U. Low-dose metronomic chemotherapy: a systematic literature analysis. Eur J Cancer (2013) 49(16):3387-95. doi:10.1016/j. ejca.2013.06.038

9. Gerber DE, Schiller JH. Maintenance chemotherapy for advanced non-small-cell lung cancer: new life for an old idea. J Clin Oncol (2013) 31(8):1009-20. doi:10.1200/JCO.2012.43.7459

10. Chessells JM, Harrison G, Lilleyman JS, Bailey CC, Richards SM. Continuing (maintenance) therapy in lymphoblastic leukaemia: lessons from MRC UKALL X. Medical Research Council Working Party in Childhood Leukaemia. Br J Haematol (1997) 98(4):945-51. doi:10.1046/j.1365-2141. 1997.3113127.x

11. Mauer AM. Therapy of acute lymphoblastic leukemia in childhood. Blood (1980) 56(1):1-10.

12. Hochster H, Weller E, Gascoyne RD, Habermann TM, Gordon LI, Ryan T, et al. Maintenance rituximab after cyclophosphamide, vincristine, and prednisone prolongs progression-free survival in advanced indolent lymphoma: results of the randomized phase III ECOG1496 Study. J Clin Oncol (2009) 27(10):1607-14. doi:10.1200/JCO.2008.17. 1561

13. Salles G, Seymour JF, Offner F, López-Guillermo A, Belada D, Xerri L, et al. Rituximab maintenance for 2 years in patients with high tumour burden follicular lymphoma responding to rituximab plus chemotherapy (PRIMA): a phase 3, randomised controlled trial. Lancet (2011) 377(9759):42-51. doi:10.1016/S0140-6736(10)62175-7

14. Zhang X, Zang J, Xu J, Bai C, Qin Y, Liu K, et al. Maintenance therapy with continuous or switch strategy in advanced non-small cell lung cancer: a systematic review and meta-analysis. Chest (2011) 140(1):117-26. doi:10.1378/chest.10-2745

15. Gennari A, Stockler M, Puntoni M, Sormani M, Nanni O, Amadori D, et al. Duration of chemotherapy for metastatic breast cancer: a systematic review and meta-analysis of randomized clinical trials. J Clin Oncol (2011) 29(16):2144-9. doi:10.1200/JCO.2010.31.5374

16. Tournigand C, Cervantes A, Figer A, Lledo G, Flesch M, Buyse M, et al. OPTIMOX1: a randomized study of FOLFOX4 or FOLFOX7 with oxaliplatin in a stop-and-Go fashion in advanced colorectal cancer - a GERCOR study. J Clin Oncol (2006) 24(3):394-400. doi:10.1200/JCO.2005.03. 0106

17. Giantonio BJ, Catalano PJ, Meropol NJ, O’Dwyer PJ, Mitchell EP, Alberts SR, et al. Bevacizumab in combination with oxaliplatin, fluorouracil, and leucovorin (FOLFOX4) for previously treated metastatic colorectal cancer: results from the Eastern Cooperative Oncology Group Study E3200. J Clin Oncol (2007) 25(12):1539-44. doi:10.1200/ JCO.2006.09.6305

18. Saltz LB, Clarke S, Díaz-Rubio E, Scheithauer W, Figer A, Wong R, et al. Bevacizumab in combination with oxaliplatin-based chemotherapy as first-line therapy in metastatic colorectal cancer: a randomized phase III study. J Clin Oncol (2008) 26(12):2013-9. doi:10.1200/JCO.2007.14. 9930

19. Markman M, Liu PY, Wilczynski S, Monk B, Copeland LJ, Alvarez RD, et al. Phase III randomized trial of 12 versus 3 months of maintenance paclitaxel in patients with advanced ovarian cancer after complete response to platinum and paclitaxel-based chemotherapy: a Southwest Oncology Group and Gynecologic Oncology Group trial. J Clin Oncol (2003) 21(13):2460-5. doi:10.1200/JCO.2003.07.013 
20. Pecorelli S, Favalli G, Gadducci A, Katsaros D, Panici PB, Carpi A, et al. Phase III trial of observation versus six courses of paclitaxel in patients with advanced epithelial ovarian cancer in complete response after six courses of paclitaxel/platinumbased chemotherapy: final results of the After- 6 protocol 1. J Clin Oncol (2009) 27(28):4642-8. doi:10.1200/JCO.2009.21.9691

21. Mei L, Chen H, Wei DM, Fang F, Liu GJ, Xie HY, et al. Maintenance chemotherapy for ovarian cancer. Cochrane Database Syst Rev (2013) 6:CD007414. doi:10.1002/14651858. CD007414.pub3

22. Aghajanian C, Blank SV, Goff BA, Judson PL, Teneriello MG, Husain A, et al. OCEANS: a randomized, double-blind, placebo-controlled phase III trial of chemotherapy with or without bevacizumab in patients with platinum-sensitive recurrent epithelial ovarian, primary peritoneal, or fallopian tube cancer. J Clin Oncol (2012) 30(17):2039-45. doi:10.1200/JCO.2012.42.0505

23. Ledermann J, Harter P, Gourley C, Friedlander M, Vergote I, Rustin G, et al. Olaparib maintenance therapy in platinum-sensitive relapsed ovarian cancer. N Engl J Med (2012) 366(15):1382-92. doi:10.1056/NEJMoa1105535

24. Du Bois A, Floquet A, Kim JW, Rau J, Campo JMD, Friedlander M, et al. Randomized, doubleblind, phase III trial of pazopanib versus placebo in women who have not progressed after firstline chemotherapy for advanced epithelial ovarian, fallopian tube, or primary peritoneal cancer (AEOC): results of an international Intergroup trial (AGO-OVAR16). J Clin Oncol (2013) 31(Suppl 18 ):LBA5503.

25. Klein R, Wielage R, Muehlenbein C, Liepa AM, Babineaux S, Lawson A, et al. Cost-effectiveness of pemetrexed as first-line maintenance therapy for advanced nonsquamous non-small cell lung cancer. J Thorac Oncol (2010) 5(8):1263-72. doi:10. 1097/JTO.0b013e3181e15d16

26. Lesnock JL, Farris C, Krivak TC, Smith KJ, Markman M. Consolidation paclitaxel is more cost-effective than bevacizumab following upfront treatment of advanced epithelial ovarian cancer. Gynecol Oncol (2011) 122(3):473-8. doi:10.1016/j. ygyno.2011.05.014

27. Lange A, Prenzler A, Frank M, Kirstein M, Vogel A, von der Schulenburg JM. A systematic review of cost-effectiveness of monoclonal antibodies for metastatic colorectal cancer. Eur J Cancer (2014) 50(1):40-9. doi:10.1016/j.ejca.2013.08.008

28. Juhász E, Kim J-H, Klingelschmitt G, Walzer S. Effects of erlotinib first-line maintenance therapy versus placebo on the health-related quality of life of patients with metastatic non-small-cell lung cancer. Eur J Cancer (2013) 49(6):1205-15. doi:10.1016/j.ejca.2012.11.006

29. Belani CP, Brodowicz T, Ciuleanu TE, Krzakowski M, Yang SH, Franke F, et al. Quality of life in patients with advanced non-small-cell lung cancer given maintenance treatment with pemetrexed versus placebo (H3E-MC-JMEN): results from a randomised, double-blind, phase 3 study. Lancet Oncol (2012) 13(3):292-9. doi:10.1016/S1470-2045(11) 70339-4

30. Peeters L, Sibille A, Anrys B, Oyen C, Dooms $\mathrm{C}$, Nackaerts $\mathrm{K}$, et al. Maintenance therapy for advanced non-small-cell lung cancer: a pilot study on patients' perceptions. J Thorac Oncol (2012) 7(8):1291-5. doi:10.1097/JTO. 0b013e31825879ea

31. Pietras K, Hanahan D. A multitargeted, metronomic, and maximum-tolerated dose "chemoswitch" regimen is antiangiogenic, producing objective responses and survival benefit in a mouse model of cancer. J Clin Oncol (2005) 23(5):939-52. doi:10.1200/JCO.2005.07.093

32. Vives M, Ginestà MM, Gracova K, Graupera M, Casanovas O, Capellà G, et al. Metronomic chemotherapy following the maximum tolerated dose is an effective anti-tumour therapy affecting angiogenesis, tumour dissemination and cancer stem cells. Int J Cancer (2013) 133(10):2464-72. doi:10.1002/ijc.28259

33. Folkins C, Man S, Xu P, Shaked Y, Hicklin DJ, Kerbel RS. Anticancer therapies combining antiangiogenic and tumor cell cytotoxic effects reduce the tumor stem-like cell fraction in glioma xenograft tumors. Cancer Res (2007) 67(8):3560-4. doi:10. 1158/0008-5472.CAN-06-4238

34. Koopman M, Simkens LH, Tije AJT, Creemers GJ, Loosveld OJ, de Jongh FE, et al. Maintenance treatment with capecitabine and bevacizumab versus observation after induction treatment with chemotherapy and bevacizumab in metastatic colorectal cancer (mCRC): the phase III CAIRO3 study of the Dutch Colorectal Cancer Group (DCCG). oral abstract session, gastrointestinal (colorectal) cancer. J Clin Oncol (2013) (suppl; abstr 3502).

35. Belani CP, Barstis J, Perry MC, La Rocca RV, Nattam SR, Rinaldi D, et al. Multicenter, randomized trial for stage IIIB or IV non-small-cell lung cancer using weekly paclitaxel and carboplatin followed by maintenance weekly paclitaxel or observation. J Clin Oncol (2003) 21(15):2933-9. doi:10.1200/ JCO.2003.02.563

36. Belani CP, Ramalingam S, Perry MC, LaRocca RV, Rinaldi D, Gable PS, et al. Randomized, phase III study of weekly paclitaxel in combination with carboplatin versus standard every-3-weeks administration of carboplatin and paclitaxel for patients with previously untreated advanced non-small-cell lung cancer. J Clin Oncol (2008) 26(3):468-73. doi:10.1200/JCO.2007.13.1912

37. Sun JF, Wu RR, Norris C, Noone A-M, AmankwaSakyi M, Slack R, et al. Safety of chronic low-dose capecitabine as maintenance therapy in gastrointestinal cancers. Gastrointest Cancer Res (2009) 3(4):134-40.

38. Choi LMR, Rood B, Kamani N, La Fond D, Packer RJ, Santi MR, et al. Feasibility of metronomic maintenance chemotherapy following high-dose chemotherapy for malignant central nervous system tumors. Pediatr Blood Cancer (2008) 50(5):970-5. doi:10.1002/pbc.21381

39. Gadducci A, Katsaros D, Zola P, Scambia G, Ballardini M, Pasquini E, et al. Weekly lowdose paclitaxel as maintenance treatment in patients with advanced ovarian cancer who had microscopic residual disease at secondlook surgery after 6 cycles of paclitaxel/platinumbased chemotherapy: results of an open noncomparative phase 2 multicenter Italian study (After-6 Protocol 2). Int J Gynecol
Cancer (2009) 19(4):615-9. doi:10.1111/IGC. 0b013e3181a4476b

40. Aurilio G, Sciandivasci E, Munzone E, Riva DF, Radice D, Bertolini F, et al. First-line therapy with metronomic capecitabine $(\mathrm{mC})$ plus docetaxel (D) followed by $\mathrm{mC}$ as maintenance for patients with HER2-negative metastatic breast cancer (MBC): preliminary analysis of a monocentric phase II trial. J Clin Oncol (2011) 29(15 suppl): e11547.

41. Kamat AA, Kim TJ, Landen CN Jr., Lu C, Han LY, Lin YG, et al. Metronomic chemotherapy enhances the efficacy of antivascular therapy in ovarian cancer. Cancer Res (2007) 67(1):281-8. doi:10.1158/ 0008-5472.CAN-06-3282

42. Guerin E, Man S, Xu P, Kerbel RS. A model of postsurgical advanced metastatic breast cancer more accurately replicates the clinical efficacy of antiangiogenic drugs. Cancer Res (2013) 73(9):2743-8. doi:10.1158/0008-5472.CAN-12-4183

43. Barber EL, Zsiros E, Lurain JR, Rademaker A, Schink JC, Neubauer NL. The combination of intravenous bevacizumab and metronomic oral cyclophosphamide is an effective regimen for platinum-resistant recurrent ovarian cancer. J Gynecol Oncol (2013) 24(3):258-64. doi:10.3802/ jgo.2013.24.3.258

44. Hecht JR, Trarbach T, Hainsworth JD, Major P, Jäger E, Wolff RA, et al. Randomized, placebocontrolled, phase III study of first-line oxaliplatinbased chemotherapy plus PTK787/ZK 222584, an oral vascular endothelial growth factor receptor inhibitor, in patients with metastatic colorectal adenocarcinoma. J Clin Oncol (2011) 29(15):1997-2003. doi:10.1200/JCO.2010.29.4496

45. Paz-Ares LG, Biesma B, Heigener D, von Pawel J, Eisen T, Bennouna J, et al. Phase III, randomized, double-blind, placebo-controlled trial of gemcitabine/cisplatin alone or with sorafenib for the first-line treatment of advanced, nonsquamous non-small-cell lung cancer. J Clin Oncol (2012) 30(25):3084-92. doi:10.1200/JCO.2011.39.7646

46. Robert NJ, Saleh MN, Paul D, Generali D, Gressot L, Copur MS, et al. Sunitinib plus paclitaxel versus bevacizumab plus paclitaxel for first-line treatment of patients with advanced breast cancer: a phase III, randomized, open-label trial. Clin Breast Cancer (2011) 11(2):82-92. doi:10.1016/j. clbc.2011.03.005

47. Bergh J, Bondarenko IM, Lichinitser MR, Liljegren A, Greil R, Voytko NL, et al. First-line treatment of advanced breast cancer with sunitinib in combination with docetaxel versus docetaxel alone: results of a prospective, randomized phase III study. J Clin Oncol (2012) 30(9):921-9. doi:10.1200/JCO.2011. 35.7376

48. Merritt WM, Nick AM, Carroll AR, Lu C, Matsuo $\mathrm{K}$, Dumble $\mathrm{M}$, et al. Bridging the gap between cytotoxic and biologic therapy with metronomic topotecan and pazopanib in ovarian cancer. $\mathrm{Mol}$ Cancer Ther (2010) 9(4):985-95. doi:10.1158/ 1535-7163.MCT-09-0967

49. Liao Z, Mason KA, Milas L. Cyclo-oxygenase-2 and its inhibition in cancer: is there a role? Drugs (2007) 67(6):821-45. doi:10.2165/00003495-20076706000001

50. Olsen SR. Taxanes and COX-2 inhibitors: from molecular pathways to clinical practice. Biomed 
Pharmacother (2005) 59(Suppl 2):S306-10. doi:10. 1016/S0753-3322(05)80052-6

51. Quinn BJ, Kitagawa H, Memmott RM, Gills JJ, Dennis PA. Repositioning metformin for cancer prevention and treatment. Trends Endocrinol Metab (2013) 24(9):469-80. doi:10.1016/j.tem. 2013.05.004

52. Leone A, Di Gennaro E, Bruzzese F, Avallone A, Budillon A. New perspective for an old antidiabetic drug: metformin as anticancer agent. Cancer Treat Res (2014) 159:355-76. doi:10.1007/978-3642-38007-5_21

53. Pasquier E, Street J, Pouchy C, Carre M, Gifford AJ, Murray J, et al. $\beta$-blockers increase response to chemotherapy via direct antitumour and anti-angiogenic mechanisms in neuroblastoma. Br J Cancer (2013) 108(12):2485-94. doi:10. 1038/bjc.2013.205

54. Pasquier E, Ciccolini J, Carre M, Giacometti S, Fanciullino R, Pouchy C, et al. Propranolol potentiates the anti-angiogenic effects and anti-tumor efficacy of chemotherapy agents: implication in breast cancer treatment. Oncotarget (2011) 2(10):797-809.
55. Duenas-Gonzalez A, Candelaria M, PerezPlascencia C, Perez-Cardenas E, de la Cruz-Hernandez E, Herrera LA. Valproic acid as epigenetic cancer drug: preclinical, clinical and transcriptional effects on solid tumors. Cancer Treat Rev (2008) 34(3):206-22. doi:10.1016/j.ctrv.2007.11.003

56. Gao Y, Lu X-C, Yang H-Y, Liu X-F, Cao J, Fan L. The molecular mechanism of the anticancer effect of atorvastatin: DNA microarray and bioinformatic analyses. Int J Mol Med (2012) 30(4):765-74. doi:10.3892/ijmm.2012.1054

57. Aftab BT, Dobromilskaya I, Liu JO, Rudin CM. Itraconazole inhibits angiogenesis and tumor growth in non-small cell lung cancer. Cancer Res (2011) 71(21):6764-72. doi:10.1158/0008-5472. CAN-11-0691

58. André N, Banavali S, Snihur Y, Pasquier E. Has the time come for metronomics in low-income and middle-income countries? Lancet Oncol (2013) 14(6):e239-48. doi:10.1016/S14702045(13)70056-1
Conflict of Interest Statement: The authors declare that the research was conducted in the absence of any commercial or financial relationships that could be construed as a potential conflict of interest.

Received: 28 January 2014; accepted: 26 March 2014; published online: 10 April 2014.

Citation: Malik PS, Raina V and André N (2014) Metronomics as maintenance treatment in oncology: time for chemo-switch. Front. Oncol. 4:76. doi: 10.3389/fonc. 2014.00076

This article was submitted to Cancer Molecular Targets and Therapeutics, a section of the journal Frontiers in Oncology.

Copyright (C) 2014 Malik, Raina and André. This is an open-access article distributed under the terms of the Creative Commons Attribution License (CC BY). The use, distribution or reproduction in other forums is permitted, provided the original author(s) or licensor are credited and that the original publication in this journal is cited, in accordance with accepted academic practice. No use, distribution or reproduction is permitted which does not comply with these terms. 